\title{
A Review on the Contemporary Research on Radio Frequency Energy Harvesting
}

\author{
Manee Sangaran Diagarajan ${ }^{1}$, Agileswari Ramasamy ${ }^{2}$, Norashidah Bt. Md Din ${ }^{3}$, Praveen Naidu Vummadisetty ${ }^{4}$ \\ ${ }^{1}$ Universiti Tenaga Nasional Malaysia \\ ${ }^{2}$ Universiti Tenaga Nasional Malaysia \\ ${ }^{3}$ Universiti Tenaga Nasional Malaysia \\ ${ }^{4}$ Velagapudi Ramakrishna Siddhartha Engineering College India \\ *Corresponding author e-mail: manee_2391@yahoo.com
}

\begin{abstract}
Radio Frequency harvesting has recently become one of the alternate approaches to power up low power wireless networks. This evolving technology opens the gate for positive energy renewal for wireless components. This paper presents a comprehensive review which includes all the important components in a RF energy harvesting system which are microstrip patch antennas, rectifier modules and power management modules. Different types of microstrip patch antennas and its designs and outputs are discussed. Rectifier modules with Schottky diodes operating under two different frequency bands are also compared and discussed. In addition, different methods of available power management circuits with different methods are also deliberated in this paper. This review also explores various key design issues and envisions some open research directions.
\end{abstract}

Keywords: Antenna modules; energy harvesting; power management; rectifier modules; radio frequency.

\section{Introduction}

In the recent times, various researches has been carried out in radio frequency (RF) energy harvesting or also known as RF energy scavenging. Many techniques has been discovered and tested under various circumstances in order to improve and optimize RF energy harvesting systems. The basic idea of a RF energy harvesting system is to convert received RF signals from an antenna and convert it into usable power. This can be considered a promoting renewable energy as it acts as a resolution to power energy constrained wireless networks. An example of an application would be the wireless sensor networks. This is because wireless sensor networks are known to have a restricted battery lifetime which turns into a drawback to the network system. Here is where a RF energy harvesting can be applied whereby it can provide a supportable power supply from a radio ambience. Consequently, this system has an important role which allows wireless devices to scavenge energy from a radio surrounding and convert it to a usable power supply. Along these lines, applications whereby RF energy harvesting systems can be implemented are quickly discovered. Various designs of circuits have been incorporated for RF energy harvesting to improvise the system to be able to convert RF into usable power. It is without a doubt that the RF energy harvesting technique is progressively emerging to be used as a renewable power source to power up low power devices.

RF devices search for electromagnetic radiation transmitted by radio devices. Radio signals are within the frequency range of 3 $\mathrm{kHz}$ up to $3 \mathrm{GHz}$. These signals are deliberated to be a medium to convey energy in a form of electromagnetic radiation. Numerous known methods have been established by previous researches under the wireless energy transfer technique. RF energy transfer and harvesting is just a part of it. Other than RF energy harvesting, different methods that are involved are inductive coupling and magnetic resonance coupling. However, regular calibration and alignment of coils is needed for inductive and magnetic resonance coupling. Hence, these methods are considered to be not suitable for charging devices remotely. On the other hand, RF energy transfer has no such impediment due to its far-field energy transfer technique. This allows RF energy to power many components dispersed in a widespread range. Since distance plays an important part, RF energy transfer has a better edge in this. However, an issue often encountered is that the system suffers from low RF-DC energy transformation. This is mainly due to the limited amount of harvested RF power from the antenna. This is considered to be a gap that needs to be filled with efficient circuitry designs. Recent designs have considered utilizing RF signals for a dual use whereby they are used to convey energy as well as transporting data.

This paper intends to deliver a review of the contemporary research and designs issues related to RF energy harvesting system. The extent of this paper covers a comparison of circuit designs which is being applied in present researches. Comparisons consist of an overview of RF energy harvesting, variations of antennas design and its associated results, RF to DC conversion approaches, output voltage attained and power management systems as well.

\section{Research Background}

A RF energy harvesting circuit would be typically equipped with an antenna, a matching network, an energy conversion module and a load. This is demonstrated in Figure 1. The RF energy source is based on the application of the system. It can either be a dedicated $\mathrm{RF}$ energy source or ambient RF energy source 


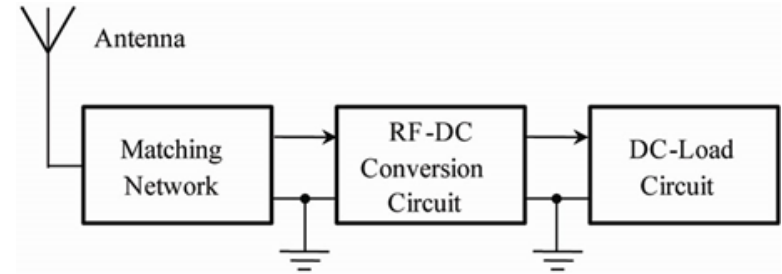

Fig 1: Typical block diagram of a RF energy harvesting system

\begin{tabular}{|c|c|c|c|c|}
\hline Source & Power & Freq & Distance & $\begin{array}{r}\text { Energy } \\
\text { Harvested }\end{array}$ \\
\hline $\begin{array}{l}\text { Isotropic } \\
\text { RF Trans- } \\
\text { mitter }\end{array}$ & $4 \mathrm{~W}$ & $\begin{array}{c}902- \\
928 \mathrm{MHz}\end{array}$ & $5 \mathrm{~m}$ & $5.5 \mathrm{uW}$ \\
\hline $\begin{array}{c}\text { Isotropic } \\
\text { RF Trans- } \\
\text { mitter }\end{array}$ & $1.78 \mathrm{~W}$ & $868 \mathrm{MHz}$ & $5 \mathrm{~m}$ & $2.3 \mathrm{uW}$ \\
\hline Cell Tower & $960 \mathrm{~kW}$ & $\begin{array}{c}674- \\
680 \mathrm{MHz}\end{array}$ & $1 \mathrm{~km}$ & $60 \mathrm{uW}$ \\
\hline $\begin{array}{c}\text { TX91501 } \\
\text { Powercast } \\
\text { Transmitter }\end{array}$ & $3 \mathrm{~W}$ & $915 \mathrm{MHz}$ & $2 \mathrm{~m}$ & $189 \mathrm{uW}$ \\
\hline $\begin{array}{c}\text { TX91501 } \\
\text { Powercast } \\
\text { Transmitter }\end{array}$ & $3 \mathrm{~W}$ & $915 \mathrm{MHz}$ & $1 \mathrm{~m}$ & $1 \mathrm{uW}$ \\
\hline
\end{tabular}

Basic function of an antenna is to transmit and receive electromagnetic waves. Antennas can be designed in a manner to operate on a single frequency band or multiple. Each antenna would have different characteristics and parameters towards a specific range of frequency. The microstrip patch antennas are often incorporated in RF energy harvesting systems due to its ease of design, fabrication, cost and size. The electrical length of the antenna determines the operating frequency of the microstrip patch antenna. The antenna can be designed accordingly to operate under a single frequency or multiple frequency band. Antennas can also be designed in a multiple cascaded or series antenna to improve directivity. The parameters and geometry design of the antenna can be varied to harvest more RF power under the designated frequency band. Since the energy density of RF diverges with frequency, the RF energy harvesting system is usually designed to function over an array of frequencies.

The next circuitry that is incorporated in a RF energy harvesting is the impedance matching circuit. Impedance matching is designed to eliminate mismatch loss. The main purpose of the circuit is to ensure maximum power delivered to the RF to DC circuit and also reduce reflected power from the antenna. This is important as it ensures the antenna to radiate and a major consideration should be taken when designing an antenna. A matching antenna consists of a progression of inductors and capacitors.

The third circuitry is the RF to DC conversion circuit. There is where the harvested RF signals will be transformed into usable $\mathrm{DC}$ voltage. To ensure an efficient conversion takes place, a rectifying circuit is executed. In order to achieve a higher DC voltage, a voltage multiplier is incorporated. By implementing diodes with lower built in voltage, higher conversion efficiency can be achieved. To ensure power is delivered smoothly to the load, a load capacitor is incorporated with the circuit.

The efficiency of a RF energy harvesting system is determined by the following factors: [2]:

- Design of the receiving antenna in terms of efficiency and gain

- Efficiency of the impedance matching in ensuring maximum power transfer

- The power efficiency of the rectifier circuit

An analytic study was performed on the quantity of RF energy harvested from different sources. Table 1 depicts the analysis results.

Table 1: Analysis Results from Various Power Sources

It can be witnessed that that the energy harvesting rate increases significantly reliant on the source power and distance. Typically, the harvested power would be in order of micro-watts. This should be sufficient for low power devices.

\section{RF Energy Harvesting Modules}

\subsection{Antenna Modules}

A series of microstrip patch antennas has been studied to analyse the performance of each antennas based on characteristics such as size, material used, application and tangent loss. Each antenna's gain, isolation and application are identified and studied. The gaps and future improvement has also been identified. Table 2 below depicts the comparison done on different types of antennas sizes, material used, application and tangent loss:

\subsection{Rectifier Modules}

To convert the RF signals which are naturally AC signals, rectifiers are used in RF energy harvesting system. This is done designing a rectifier which is usually integrated with a diode as the main component. This paper depicts a study on the rectifier element or a Schottky diode circuit to conclude the efficiency it contributes to the RF energy harvesting system. In order to effectively convert the antenna surface incident RF power to usable DC, a high efficiency RF to DC circuit is required. Many past researches has studied that the RF to DC circuit's efficiency relies upon a few factors. These are the Schottky diode type and forward voltage, load resistance, harmonics, spurious emissions and also the ability of the circuit to handle incident waves.

Figure 2, is a plot on RF energy conversion efficiencies versus the input power. The plot is also based on different operating frequency. From the plot, as the input power increases, the efficiencies tend to increase as well. This is because the circuitry suffers low losses due to the diode threshold voltage. At high powers, higher efficiencies can be attained as the harvesting devices are functioning on a linear state which means it is far above their diode turnon voltage. Opposite to this, as the power level decreases, the device efficiency decreases as well. This is because the diode will be on an operating state when it detects a smaller fraction of RF signal. It also can be observed that as the frequency increases, the efficiency of the devices increases.

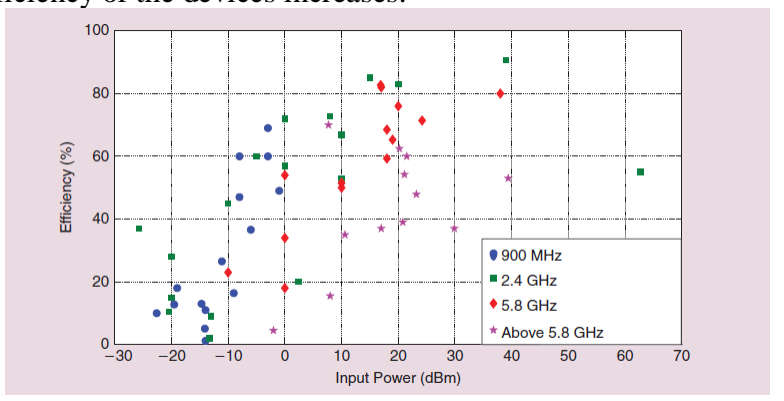

Fig 2: Input power vs conversion efficiency

Table 3 delineates an investigation for energy conversion modules that has been coordinated with RF energy harvesting systems throughout the years. However, a portion of the systems efficiencies are contributed by the receiving antenna and matching circuit system also and not exclusively considering the rectifier circuit. The circuit efficiencies depend on an assortment of advancements and varying loads because of their uses in remote power exchange applications. This paper presents comes about considering GSM $900 \mathrm{MHz}$ band and ISM 2.45GHz. Now and again, multiband [3-5] frameworks are intended to exploit the encompassing RF energy from various bands. This survey presents rectifiers which are being utilized for single frequency excitation. 
Table 2: Comparison on Types of Microstrip Patch Antenna

put voltage of $1 \mathrm{~V}$ is achieved by this system. The power manage-

\begin{tabular}{|c|c|c|c|c|c|c|c|c|}
\hline Ref. & $\operatorname{Size}(\mathbf{m m})$ & $\operatorname{Area}(\mathbf{m m} 2)$ & $\begin{array}{l}\text { Tangent } \\
\text { loss }\end{array}$ & Material & $\begin{array}{l}\text { Operating } \\
\text { Range } \\
(\mathbf{G H z})\end{array}$ & $\begin{array}{l}\text { Isolation } \\
\text { (dB) }\end{array}$ & Gain(dBi) & Application \\
\hline [6] & $48 * 115 * 0.8$ & 4416 & & FR4 & $2.3-7.7$ & & 4.5 & WLAN \\
\hline [7] & $25 * 40 * 1.55$ & 1550 & 0.015 & FR4 & $3.1-5.12$ & $>26$ & 4.5 & USB dongle \\
\hline [8] & $30 * 50.5 * 1$ & 1515 & 0.02 & FR4 & $4-10$ & 20 & & MIMO \\
\hline [9] & $50 * 90 * 1.52$ & 6840 & 0.02 & FR4 & $1.8-10.6$ & 10 & 1.22 & $\begin{array}{l}\text { GSM/LTE/WLAN with } \\
\text { UWB }\end{array}$ \\
\hline [10] & $74 * 44 * 1$ & 3256 & & FR4 & $\begin{array}{l}3.1-8.3,9.4- \\
10.1\end{array}$ & & & WPAN,WLAN \\
\hline [11] & $60 * 64 * 1.6$ & 6144 & & FR4 & $2.3-10.4$ & & 4.15 & PDA phone \\
\hline [12] & $40 * 30 * 1$ & 1200 & & FR4 & $\begin{array}{l}2.39- \\
3.75,5.3-7\end{array}$ & $\begin{array}{l}<-20 \\
<-25\end{array}$ & 2.5 & WIMAX/WLAN \\
\hline [13] & $38 * 43 * 1.6$ & 26144 & 0.02 & FR4 & $\begin{array}{l}2.34- \\
2.55,5.13- \\
5.85\end{array}$ & $\begin{array}{l}>27 \\
40\end{array}$ & & WLAN \\
\hline [14] & $45 * 89.6 * 1.6$ & 64512 & 0.02 & FR4 & $\begin{array}{l}2.34- \\
2.95,3.38- \\
3.75 \\
4.4-6.7\end{array}$ & $>=20$ & & $\begin{array}{l}\text { Wireless communica- } \\
\text { tion systems }\end{array}$ \\
\hline [15] & $22 * 45 * 1.6$ & 1584 & 0.02 & FR4 & $2-2.5$ & $<20$ & & USB dongle \\
\hline [16] & $20 * 50 * 0.4$ & 400 & 0.0245 & FR4 & $2.4-2.484$ & $>17.8$ & & WLAN \\
\hline [17] & $60 * 95 * 0.8$ & 4560 & & FR4 & $1.88-2.20$ & $>11.5$ & 1.5 & Mobile Phones \\
\hline [18] & $23 * 5 * 4$ & 460 & & & $2.48-2.52$ & $>20$ & 9.3 & MIMO \\
\hline [19] & $10 * 17.5 * 1.6$ & 280 & 0.02 & FR4 & $\begin{array}{l}2.2-2.5,2.7- \\
4,4-6.5\end{array}$ & & 2.6 & $\begin{array}{l}\text { Wireless communica- } \\
\text { tion }\end{array}$ \\
\hline [20] & $36 * 36 * 1.6$ & 2073.6 & & FR4 & $2.4-11$ & & 6.5 & UWB \\
\hline
\end{tabular}

Table 3: Energy Conversion Efficiencies for GSM and ISM

\begin{tabular}{|c|c|c|c|c|}
\hline $\begin{array}{l}\text { Input } \\
\text { Power } \\
(\mathrm{dBm})\end{array}$ & $\begin{array}{l}\text { Frequency } \\
(\mathrm{MHz})\end{array}$ & Rectifier Element & $\begin{array}{l}\text { Efficiency } \\
(\%)\end{array}$ & Reference \\
\hline-13.3 & 2450 & $\begin{array}{l}\text { Skyworks } \\
\text { SMS7630 } \\
\text { Si Schottky }\end{array}$ & 2.01 & [21] \\
\hline-13 & 2450 & $\begin{array}{l}\text { Skyworks } \\
\text { SMS7630 } \\
\text { Si Schottky }\end{array}$ & 9 & [22] \\
\hline-20.4 & 2450 & $\begin{array}{l}\text { Skyworks } \\
\text { SMS7630 } \\
\text { Si Schottky }\end{array}$ & 10.5 & [23] \\
\hline-20 & 2450 & $\begin{array}{l}\text { Avago HSMS-2852 } \\
\text { Si Schottky }\end{array}$ & 15 & [24] \\
\hline 2.4 & 2450 & $\begin{array}{l}\text { Skyworks } \\
\text { SMS7630 } \\
\text { Si Schottky (array) }\end{array}$ & 20 & [25] \\
\hline-14 & 915 & $\begin{array}{l}\text { 90-nm CMOStran- } \\
\text { sistor }\end{array}$ & 11 & [26] \\
\hline-19.5 & 900 & $\begin{array}{l}\text { 0.18-nm CMOS, } \\
\text { CoSi2 -Si Schottky }\end{array}$ & 128 & {$[27]$} \\
\hline-14.7 & 900 & $\begin{array}{l}\text { 0.35-nm CMOS- } \\
\text { transistor }\end{array}$ & 13 & [28] \\
\hline-9 & 963 & $\begin{array}{l}0.35-\mathrm{nm} \text { CMOS } \\
\text { transistor }\end{array}$ & 164 & [29] \\
\hline
\end{tabular}

\subsection{Power Management}

This section will discuss on the existing power management modules that are available that is being integrated with energy harvesting. Power management is important as it controls the input DC impedance and incorporates and algorithm for more efficient and high performing circuits. In [30], a compact antenna is designed to operate in $2.45 \mathrm{GHz}$ frequency band. A series of Schottky diodes are used as the rectifying circuit for this RF energy harvester. The power management introduced here is a Flyback converter. This converter is used to improve the impedance matching. A DC out- ment includes a MPPT algorithm which is controlled by a start circuit. The function of the start-up circuit is it boosts the DC output from the rectifier and this can be done a low power situation. A start-up capacitor is present and will be charged to a sufficient level via an under voltage lock out circuit. This is done before the control circuit converter starts operating. The power can be harvested and used right away or can be harvested, stored and used later on depending on the requirement.

This system in [31] consists of a multi power management system. It works by having a multi energy source and a multi load energy harvesting system. Thermal, vibration and radio frequency are the energy sources for this system. An algorithm is designed whereby different energy states are defined via the charge state of a supercapacitor or a battery. A simple capacitor will be sufficient for the power management algorithm to work. Capacitor will be the vital component utilized in this system to perform the switching from one state to another. It is used to monitor the power balance of the conversion system.

A MPPT based power management is incorporated in [32] whereby a Microntroller Unit (MCU) is being used to manage the power The RF energy harvesting system consists of a rectenna array together with a voltage regulator. The Texas Instruments MSP430 Microcontroller was used to run the MPPT algorithms which generates control signals and optimizes the received power. The rectifier output of the system is sensed to calculate the input power whereas the output voltage is utilized for battery charge control. A high adaptive optimization algorithm is applied here in order to ensure high conversion efficiency.

In [33], a power management circuit is designed with a boost converter and a control circuit together with MPPT. Maximum power point tracking (MPPT) is achieved at the output of the RD to DC rectifier to the input of the rectifier. This is done by implementing a rectification algorithm on the input voltage and is utilized to ensure lower energy loss at the output capacitor of the boost converted. The MPPT is able to provide an efficient output at a great range of input power. The matching impedance at the output of the $\mathrm{RF}$ to DC rectifier is maintained and yet an efficient output can be 
achieved. The circuit was designed in 180nm mixed mode CMOS. For a $-10 \mathrm{dBm}$ input power from an antenna resonating at 950 $\mathrm{MHz}$, and output voltage of $1 \mathrm{~V}$ is achieved. With a load resistance of $76 \mathrm{k} \Omega$, the boost conversion efficiency was measured to be at $80 \%$.

A novel power management method is being introduced in [34] which is the adaptive thresholding power management (ATPM). This power management method is incorporated into embedded systems which are being powered by renewable energy. For example, a solar-powered wireless sensor network that collects information needs to have a RF circuit that could send out the data collected. The power management unit gathers information such as average power from the energy harvesting unit and energy status of the battery. A channel gain that resides in the RF circuit will determine whether to turn on the RF circuit for additional power or not.

A RF energy harvesting system operating at $2.45 \mathrm{GHz}$ were designed in [35] whereby the system is designed with a boost converter. The battery is charged with power as low as -20dBM. This is achieved by the power management system. The battery charge is built with an array of transistors. The reason to this is that the boost converter will be able to raise the voltage to the charging circuit and consecutively supply the energy into the battery.

In [36] a circularly polarized antenna operating at $2.45 \mathrm{GHz}$ is designed with a power management circuit. The Power management framework comprises of two phases. In the primary stage, the RF power harvested by the antenna is rectified utilizing a Dickson voltage multiplier with a impedance matching circuit. In the second stage, the output voltage is additionally boosted to a level to charge a lithium-ion battery. The second stage used a Texas Instrument BQ25504. The chip incorporates a DC-DC converter and a battery management algorithm. A low quiescent current $(80 \mathrm{mv})$ requirement makes it the most appropriate for low power RF energy scavenging circuits among every other ICs available right now.

\section{Gaps and Challenges}

For the past 10 years, the research towards RF harvesting energy has expanded. The main motivation of this study is would be to power up the low power gadgets by utilizing the ambient RF energy sources. Some good examples of this are signals from cells phones or wireless modems and television frequency bands. The main issue faced here is that the power scavenged from the ambient sources is low compared to a dedicated RF source. This is due to many factors which will be discussed in detail. Subsequently, it represents a huge research challenge in expanding the proficiency of the energy harvesting framework notwithstanding for lowpowered gadgets. A lot of research and white papers has been published in finding out the issues with the RF energy harvesting system. Table 4 gives a comprehensive comparison on the existing RF energy harvesting circuits.

Based on the points discussed, there are still gaps that can be addressed for further research in RF energy harvesting. Distance plays an important role as the signal suffers in path losses which cause very low power scavenging for RF energy harvesting. To have an efficient and beneficial RF energy harvesting system, the distance from the RF source should be as far as possible.

Other than transfer distance, the direction and the gain of the receiving antenna also plays a major role in determining the RF energy harvesting rate. To achieve higher harvesting rates, designing a high antenna based on materials and geometry for a wide range of frequency is an important research issue. Broadband antennas will be beneficial for RF energy harvesting as it could harvest RF power from a wider spectrum. The challenge here is that microstrip patch antennas are naturally weak in achieving wide bandwidth.

Another gap that needs to be addressed under the topic of RF energy harvesting is impedance mismatching. Impedance mismatch happens when the input resistance and reactance of the rectifier mismatches with the receiving microstrip patch antenna. If this is the case, then the antenna will not be able to transfer all the scavenged energy from the RF signals to the rectifier. Thus, impedance variations can impact the energy conversion efficiency. Due to this, there is a need for a circuit development whereby the circuit will be able to tune the parameters automatically to minimize the impedance mismatch to allow maximum power transfer.

Next, there is also room for improvement on the RF to DC conversion efficiency. The efficiency of the circuitry depends highly on the density of harvested RF power. The RF to DC conversion efficiency should be improved when the harvested power is low at the input itself. Besides this, introducing a high efficient low power DC to DC converter would convert a source of DC from a voltage level to another. This would be another method to achieve high efficiency on the RF energy harvesting system. Various studies have been done with different types of diodes and stage capacitors to achieve a high DC output. Integrating the system with a suitable DC to DC controller or a power management would help in achieving higher DC output.

Another important challenge to look into is the position or location of the RF source. A proper line-of-sight needs to be present to ensure efficient energy transfer. Hence, the RF energy source is to be located in a suitable location in order to support multiple receivers to be charged. Another point is that most of the researches are considering powering low power sensors and devices. Not much research is being carried out to power mobile phones via RF energy harvesting. This can be considered to create charge less mobile phones. Another lacking area of research in RF energy harvesting is power management. Based on the table, most of the researches did not include a power management system. The challenge in implementing a power management circuit in RF energy harvesting is that sufficient power is required to run the power management algorithm and at the same time it the system should be able to power up the load devices as well. Besides that, in the absence of RF energy, the system will not be able to power up the load devices. This can be countered by implementing a storage circuit together with the power management for the storage circuit to take over the system and power up the load devices instead when there is no RF source. 
Table 4: Comparison on Existing RF Enery Harvesting Circuits

\begin{tabular}{|c|c|c|c|c|c|c|}
\hline Frequency & Antenna Type & Rectifier type & Distance & $\begin{array}{l}\text { DC Output } \\
\text { Voltage/Power }\end{array}$ & Reference & Remarks \\
\hline $906 \mathrm{MHz}$ & - & $\begin{array}{l}\text { CMOS Technolo- } \\
\text { gy Process }\end{array}$ & $\begin{array}{l}\text { Load at } \\
15 \mathrm{~m}\end{array}$ & $1.0 \mathrm{~V}$ & [37] & Short distance from source \\
\hline $906 \mathrm{MHz}$ & $\begin{array}{l}\text { Resonance circuit } \\
\text { tuning }\end{array}$ & $\begin{array}{l}\text { Schottky diode } \\
\text { charge pump }\end{array}$ & - & $0.3 \mathrm{~V}$ & {$[38]$} & $\begin{array}{l}\text { Low output due to inefficient } \\
\text { antenna }\end{array}$ \\
\hline $950 \mathrm{MHz}$ & Square microstrip & $\begin{array}{l}\text { Schottky diode 6- } \\
\text { stage voltage } \\
\text { doubler }\end{array}$ & $50 \mathrm{~m}$ & $0.87 \mathrm{~V}$ & [39] & No power management \\
\hline $\begin{array}{l}2.4 \mathrm{GHz} \text { ISM } \\
\text { Band }\end{array}$ & $\begin{array}{l}\text { Microstrip patch } \\
\text { antenna }\end{array}$ & Super capacitor & 1 to $2 \mathrm{~m}$ & $3.6 \mathrm{~V}$ & [40] & Short distance from source \\
\hline $531-1611 \mathrm{KHz}$ & $\begin{array}{l}\text { Microstrip patch } \\
\text { antenna }\end{array}$ & $\begin{array}{l}5 \text { stage Villard } \\
\text { voltage doubler }\end{array}$ & - & $2.8 \mathrm{~V}$ & [41] & No power management \\
\hline $915 \mathrm{MHz}$ & $\begin{array}{l}\text { Multiple square } \\
\text { patch antenna }\end{array}$ & $\begin{array}{l}\text { CMOS Technolo- } \\
\text { gy Process }\end{array}$ & - & $5 \mathrm{~V}$ & [42] & Dedicated RF source \\
\hline $\begin{array}{l}400 \mathrm{MHz} \& 2.4 \\
\mathrm{GHz}\end{array}$ & $\begin{array}{l}\text { Dual polarized patch } \\
\text { antenna }\end{array}$ & $\begin{array}{l}3 \text { stage Villard } \\
\text { voltage doubler }\end{array}$ & - & $1.8 \mathrm{~V}$ & [43] & Addresses low power sensors \\
\hline $\begin{array}{l}\text { DTV, GSM } \\
900, \text { GSM } 1800 \\
\& 3 \mathrm{G}\end{array}$ & $\begin{array}{l}\text { Folded-dipole an- } \\
\text { tennas }\end{array}$ & Zero-bias diodes & - & $5 \mu \mathrm{W} / \mathrm{cm}^{3}$ & {$[44]$} & Dedicated RF source \\
\hline 674-680 MHZ & $\begin{array}{l}\text { Broadband log peri- } \\
\text { odic antenna }\end{array}$ & $\begin{array}{l}\text { 4-stage voltage } \\
\text { doubler circuit }\end{array}$ & $4.1 \mathrm{Km}$ & $1.5 \mathrm{~V}$ & [45] & No power management \\
\hline $\begin{array}{l}\text { 935.2-959.8 } \\
\mathrm{MHz}\end{array}$ & $\begin{array}{l}\text { E-Shaped partial } \\
\text { ground }\end{array}$ & $\begin{array}{l}\text { Schottky diode } 7- \\
\text { stage }\end{array}$ & $400 \mathrm{~m}$ & $3.9 \mathrm{~V}$ & {$[46]$} & No power management \\
\hline $\begin{array}{l}2.45 \mathrm{GHz} \text { ISM } \\
\text { Band }\end{array}$ & Compact antenna & $\begin{array}{l}\text { Combination of } \\
\text { Schottky diodes }\end{array}$ & $1 \mathrm{~m}$ & $1 \mathrm{~V}$ & [47] & Short distance from source \\
\hline $\begin{array}{l}2.45 \mathrm{GHz} \text { ISM } \\
\text { Band }\end{array}$ & $\begin{array}{l}\text { Rectangular strip- } \\
\text { loop antenna }\end{array}$ & Schottky Diode & $2 m$ & $0.55 \mathrm{~V} / 1.44 \mathrm{~V}$ & [48] & $\begin{array}{l}\text { Short distance from source and } \\
\text { low output }\end{array}$ \\
\hline $\begin{array}{l}2.45 \text { GHZ ISM } \\
\text { Band }\end{array}$ & $\begin{array}{l}\text { Multiple microstrip } \\
\text { patch antenna }\end{array}$ & $\begin{array}{l}\text { Greinacher quad- } \\
\text { rupled rectifier } \\
\text { circuit }\end{array}$ & - & $\begin{array}{l}\text { Charged } 33 \mathrm{mF} \\
\text { supercapacitor } \\
\text { at } 1.6 \mathrm{~V}\end{array}$ & [49] & No power management \\
\hline $\begin{array}{l}2.45 \mathrm{GHz} \text { ISM } \\
\text { Band }\end{array}$ & $\begin{array}{l}\text { Dielectric circular } \\
\text { patch antenna }\end{array}$ & $\begin{array}{l}\text { Single stage volt- } \\
\text { age doubler RF } \\
\text { Detector diodes }\end{array}$ & $550 \mathrm{~mm}$ & $1.4 \mathrm{~V}$ & {$[50]$} & Short distance from source \\
\hline $900 \mathrm{MHz}-3 \mathrm{GHz}$ & Broadband antenna & $\begin{array}{l}\text { Single stage volt- } \\
\text { age doubler circuit }\end{array}$ & - & $1.5 \mathrm{~V}$ & {$[51]$} & $\begin{array}{l}\text { Low RF to DC conversion } \\
\text { efficiency }\end{array}$ \\
\hline $520-590 \mathrm{MHz}$ & Broadband antenna & $\begin{array}{l}\text { Schottky Single } \\
\text { stage voltage } \\
\text { double circuit }\end{array}$ & - & $\begin{array}{l}0.0015 \mu \mathrm{W}-53 \\
\mu \mathrm{W} \text { for input } \\
\text { power of }-10 \text { to } \\
40 \mathrm{dBm}\end{array}$ & {$[52]$} & $\begin{array}{l}\text { Low RF to DC conversion } \\
\text { efficiency }\end{array}$ \\
\hline $900 \mathrm{MHz}$ & $\begin{array}{l}\text { Microstrip patch } \\
\text { antenna }\end{array}$ & $\begin{array}{l}\text { 4-Stage Cascaded } \\
\text { MOSFET rectifier }\end{array}$ & - & $1.1 \mathrm{~V}$ & [53] & No power management \\
\hline $\begin{array}{l}\text { GSM900 } \\
\text { GSM1800 }\end{array}$ & Q-coil antenna & $\begin{array}{l}\text { Schottky diode } \\
\text { rectifier }\end{array}$ & - & $2 \mathrm{~V}$ & [54] & No power management \\
\hline
\end{tabular}




\section{Conclusion}

A study and analysis of existing RF energy harvesting systems are discussed. Different antenna modules under different frequency bands are compared. The gaps and drawbacks are identified and the resulting output is also discussed. Rectifier modules based on Schottky diodes are discussed under two different frequency bands which is the GSM band and ISM band. Efficiencies of the rectifier modules are deliberated by relating the input power and the frequency band. Later, power management modules were discussed whereby different methods were compared. Paper was concluded by discussing the design issues in RF energy harvesting which can be used for upcoming researches.

\section{Acknowledgement}

This work is supported by the Ministry of Science, Technology and Innovation Malaysia (no.03-02-03-SF0291).

\section{References}

[1] L. Xie, Y. Shi, Y. T. Hou and W. Lou, "Wireless power transfer and applications to sensor networks," IEEE Wireless Communications Magazine, vol. 20, no. 4, pp. 140-145, August 2013.

[2] Xiao, L., Wang, P, Niyato, D.; Kim, D and Han, Z., "Wireless Networks with RF Energy Harvesting: A Contemporary Survey," Communications Surveys \& Tutorials, IEEE, vol.PP, no.99, pp.1,1

[3] M. Erol-Kantarci and H. T. Mouftah, "Mission-aware placement of RF-based power transmitters in wireless sensor networks," in Proc. IEEE Symposium on Computers and Communications (ISCC), pp. 12-17, Cappadocia, July 2012.

[4] M. Erol-Kantarci and H.T. Mouftah, "DRIFT: differentiated RF power transmission for wireless sensor network deployment in the smart grid," in Proc. IEEE Globecom Workshops, pp. 1491-1495, Anaheim, CA, Dec. 2012.

[5] Le, T.; Mayaram, K.; Fiez, T., "Efficient Far-Field Radio Frequency Energy Harvesting for Passively Powered Sensor Networks," Solid-State Circuits, IEEE Journal of, vol.43,

[6] Wong, Kin-Lu \& Su, Saou-Wen \& Kuo, Yen-Liang. (2003). Printed ultra-wideband diversity monopole antenna. Microwave and $\mathrm{Op}$ tical Technology Letters. 38.257 - 259. 10.1002/mop.11031.

[7] Zhang, Shuai \& Kiong Lau, Buon \& Sunesson, Anders \& He, Sail ing. (2012). Closely-Packed UWB MIMO/Diversity Antenna with Different Patterns and Polarizations for USB Dongle Applications. IEEE Transactions on Antennas and Propagation. 60.

[8] Bilal, Muhammad \& Saleem, Rashid \& Shafique, Muhammad \& A. Khan, Hassan. (2014). MIMO application UWB antenna doublet incorporating a sinusoidal decoupling structure. Microwave and Optical Technology Letters. 56. 10.1002/mop.28387.

[9] K. Dhar, Sagar \& Sharawi, Mohammad. (2015). A UWB semi-ring MIMO antenna with isolation enhancement. Microwave and Optical Technology Letters.

[10] Gogosh, Nayab \& Shafique, Muhammad \& Saleem, Rashid. (2013). An UWB Diversity Antenna Array with a Novel H type Decoupling Structure. Microwave and Optical Technology Letters.

[11] Hong, Seokjin \& Chung, Kyungho \& Lee, Jaewon \& Jung, Sangwook \& Lee, Sang-Sun \& Choi, Jaehoon. (2008). Design of a diversity antenna with stubs for UWB applications. Microwave and Optical Technology Letters

[12] Xiong, Ling \& Gao, Peng. (2012). Compact dual-band printed diversity antenna for WiMAX/WLAN applications. Progress in Electromagnetics Research C. 32. 151-165. 10.2528/PIERC12063001.

[13] J. Y. Lee, S. H. Kim, J. H. Jang, "Reduction of Mutual Coupling in PlanarMultiple Antenna by Using 1-D EBG and SRR Structures", IEEE Trans. on Antennas and Propagation, vol. 63, no. 9, pp. 4194-4198, Sep. 2015.

[14] Li, J.-F \& Chu, Q.-X \& Guo, X.-X. (2011). Tri-band four-element MIMO antenna with high isolation. Progress In Electromagnetics Research C. 24. 10.2528/PIERC11082305.

[15] Luyu Zhao, Lap K. Yeung, Ke-Li Wu, "A novel second-order decoupling network for two-element compact antenna arrays", $\mathrm{Mi}$ crowave Conference Proceedings (APMC) 2012 Asia-Pacific, pp. 1172-1174, 2012.

[16] Chen, Wen Shan \& Lin, Chi Huang \& Lee, Bau Yi \& Hsu, Wen Hsiu \& Chang, Fa Shian. (2012). Monopole slot antenna design for
WLAN MIMO application. Microwave and Optical Technology Letters. 54. 10.1002/mop.26740.

[17] Ding, Yuan \& Zhengwei, Du \& Ke, Gong \& Zhenghe, Feng. (2007). A Four-Element Antenna System for Mobile Phones. Antennas and Wireless Propagation Letters, IEEE. 6.

[18] Foez Ahmed, Ying Feng, Ronglin Li, "Dual wide-band four-unit MIMO antenna system for 4G/LTE and WLAN mobile phone applications", Antennas and Propagation Conference (LAPC) 2013 Loughborough, pp. 202-207, 2013.

[19] Naidu Vummadisetty, Dr. Praveen \& Kumar, Raj. (2015). A very small asymmetric coplanar strip fed multi-band antenna for wireless communication applications. Microsystem Technologies.

[20] Malekpour, Narges \& Honarvar, M. (2016). Design of highisolation compact MIMO antenna for UWB application. ProgressiIn Electromagnetics Research C. 62.

[21] J. Curty, N. Joehl, C. Dehollain and M. Declercq, "Remotely powered addressable UHF RFID integrated system," IEEE J. SolidState Circuits, vol. 40, no. 11, pp. 2193-2202, Nov. 2005.

[22] U. Olgun, C. Chen and J. Volakis, "Investigation of rectenna array configurations for enhanced RF power harvesting," IEEE Antennas Wireless Propag. Lett., vol. 10, pp. 262-265, Apr. 2011.

[23] S. Mbombolo and C. Park, "An improved detector topology for a rectenna," in IMWS-IWPT, 2011, pp. 23-26.

[24] J. Hagerty, F. Helmbrecht, W. McCalpin, R. Zane and Z. Popovic,"Recycling ambient microwave energy with broad-band rectenna arrays," IEEE Trans. Microwave Theory Tech., vol. 52, no. 3, pp. 1014-1024, Mar. 2004.

[25] Farinholt, Kevin M.; Park, G.; Farrar, C.R., "RF Energy Transmission for a Low-Power Wireless Impedance Sensor Node," Sensors Journal, IEEE, vol.9, no.7, pp.793,800, July 2009

[26] U. Karthause and M. Fischer, "Fully integrated passive UHF RFID transponder IC with 16.7-nW minimum RF input power," IEEE J. Solid-State Circuits, vol. 38, no. 10, pp. 1602-1608, Oct. 2003.

[27] J. Yi, W. Ki and C. Tsui, "Analysis and design strategy of UHF micro-power CMOS rectifiers for micro-sensor and RFID applications," IEEE Trans. Circuits Syst., vol. 54, no. 1, pp. 153-166, Jan. 2007.

[28] D. Liu, F. Li, X. Zou, Y. Liu, X. Hui and X. Tao, "New analysis and design of a RF rectifier for RFID and implantable devices," Sensors, vol. 11, pp. 6494-6508, June 2011.

[29] D. Masotti, A. Costanzo, M. Del Prete and V. Rizzoli, "Genetic based design of a tetra-band high-efficiency radio-frequency energy harvesting system," IET Microwaves, Antennas Propagation., vol. 7, no. 15, pp. 1254-1263, June 2013.

[30] N. Kong and D. S. Ha, "Low-Power Design of a Self-powered Piezoelectric Energy Harvesting System With Maximum Power Point Tracking," in IEEE Transactions on Power Electronics, vol. 27, no. 5, pp. 2298-2308, May 2012.

[31] Weddell, A.S., Magno, M., Merrett, G.V., Brunelli, D., Al-Hashimi, B.M., \& Benini, L. (2013). A survey of multi-source energy harvesting systems. 2013 Design, Automation \& Test in Europe Conference \& Exhibition (DATE), 905-908.

[32] Pinuela, M.; Mitcheson, P.D.; Lucyszyn, S., "Ambient RF Energy Harvesting in Urban and Semi-Urban Environments," in Proc. Microwave Theory and Techniques, IEEE Transactions, Asia Pacific on, vol.61, no.7, pp.2715,2726, July2013

[33] F. Pulvirenti, A. La Scala, D. Ragonese, K. D'Souza, G. M. Tina and S. Pennisi, "4-Phase Interleaved Boost Converter With IC Controller for Distributed Photovoltaic Systems," in IEEE Transactions on Circuits and Systems I: Regular Papers, vol. 60, no. 11, pp. 3090-3102, Nov. 2013

[34] W. Tang and L. Wang, "Data rate maximization by adaptive thresholding RF power management under renewable energy," 2010 IEEE International Conference on Computer Design, Amsterdam, 2010, pp. 145-150.

[35] Hidayah, Noor \& Mohd Yunus, Noor \& Sampe, Jahariah \& Yunas, Jumril \& Pawi, Alipah. (2017). MEMS Based RF Energy Harvester for Battery-Less Remote Control: A Review. American Journal of Applied Sciences. 14. 10.3844/ajassp.2017.316.324.

[36] M. Piñuela, P. D. Mitcheson and S. Lucyszyn, "Ambient RF Energy Harvesting in Urban and Semi-Urban Environments," in IEEE Transactions on Microwave Theory and Techniques, vol. 61, no. 7, pp. 2715-2726, July 2013.

[37] Le, T.; Mayaram, K.; Fiez, T., "Efficient Far-Field Radio Frequency Energy Harvesting for Passively Powered Sensor Networks," Solid-State Circuits, IEEE Journal of, vol.43,

[38] Ungan, T.; Reindl, L.M., "Harvesting Low Ambient RF-Sources for Autonomous Measurement Systems," Instrumentation and Measurement Technology Conference Proceedings, 2008. IMTC 2008. IEEE, vol., no., pp.62, pg 65,12-15May200 
[39] Arrawatia, M, Baghini, M.S and Kumar, G., "RF energy harvesting system from cell towers in $900 \mathrm{MHz}$ band," in Proc. Communications (NCC), 2011 National Conference, Bangalore on vol., no., pp.1,5, 28-30Jan.2011

[40] Farinholt, Kevin M.; Park, G.; Farrar, C.R., "RF Energy Transmission for a Low-Power Wireless Impedance Sensor Node," Sensors Journal, IEEE, vol.9, no.7, pp.793,800, July 2009

[41] Aminov,P and Agrawal, J.P., "RF Energy Harvesting," in Proc. Electronic Components and Technology Conference (ECTC), 2014 IEEE 64th, San Diego CA, vol., no., pp.1838,1841, 27-30 May 2014

[42] Minhong Mi; Mickle, M.H.; Capelli, C.; Swift, H., "RF energy harvesting with multiple antennas in the same space," Antennas and Propagation Magazine, IEEE, vol.47, no.5, pp.100,106, Oct.2005

[43] Jabbar, H.; Song, Y.S.; Jeong, T.T., "RF energy harvesting system and circuits for charging of mobile devices," Consumer Electronics, IEEE Transactions on, vol.56, no.1, pp.247,253, February2010

[44] Pinuela, M.; Mitcheson, P.D.; Lucyszyn, S., "Ambient RF Energy Harvesting in Urban and Semi-Urban Environments," in Proc. Microwave Theory and Techniques, IEEE Transactions, Asia Pacific on, vol.61, no.7, pp.2715,2726, July2013

[45] Devi, K.K.A.; Norashidah, M.D.; Chakrabarty, C.K. and Sadasivam, S., "Design of an RF-DC conversion circuit for energy harvesting," in Proc. Electronics Design, Systems and Applications (ICEDSA), 2012 IEEE International Conference, Kuala Lumpure, on, vol., no., pp.156,161, 5-6 Nov. 2012

[46] Harouni, Z, Cirio, L.; Osman, L.; Gharsallah, A and Picon, O., "A Dual Circularly Polarized 2.45-GHz Rectenna for Wireless Power Transmission," Antennas and Wireless Propagation Letters, IEEE, vol.10, no., pp.306,309, 2011

[47] Adami, Salah-Eddine; Vollaire, Christian; Allard, Bruno; Costa, Francois; Haboubi, Walid and Cirio, Laurent, "Ultra-low Power Autonomous Power Management System with Effective Impedance Matching for RF Energy Harvesting," in Proc. Integrated Power Systems (CIPS), 2014 8th International Conference on, vol., no., pp.1,6, 25-27 Feb. 2014

[48] Ensworth, J.F.; Thomas, S.J.; Seung Yul Shin and Reynolds, M.S., "Waveform-aware ambient RF energy harvesting," in Proc of RFID (IEEE RFID), 2014 IEEE International Conference on, vol., no., pp.67,73, 8-10 April 2014

[49] Takhedmit, H, Cirio, L, Costa, F and Picon, O., "Transparen rectenna and rectenna array for RF energy harvesting at $2.45 \mathrm{GHz}$," in Proc. Antennas and Propagation (EuCAP), 2014 8th European Conference, Hague on, vol., no., pp.2970,2972, 6-11 April 2014

[50] Alneyadi, F, Alkaabi, M,Alketbi, S, Hajraf, S and Ramzan, R., "2.4GHz WLAN RF energy harvester for passive indoor sensor nodes," in Proc. Semiconductor Electronics (ICSE), 2014 IEEE International Conference on , vol., no., pp.471,474, 27-29 Aug. 2014+

[51] Gudan, K, Chemishkian, S, Hull, J.J, Thomas, S.J.; Ensworth, J and Reynolds, M.S., "A $2.4 \mathrm{GHz}$ ambient RF energy harvesting system with $-20 \mathrm{dBm}$ minimum input power and NiMH battery storage," in Proc. RFID Technology and Applications Conference (RFID-TA), Las Vegas, 2014 IEEE, vol., no., pp.7,12, 8-9 Sept. 2014

[52] Xudong Wang; Zhengming Zhao; Guanhua Chen; Fanbo He, "RF energy harvesting with broadband antenna," in Proc of Transportation Electrification Asia-Pacific (ITEC Asia-Pacific), 2014 IEEE Conference and Expo, vol., no., pp.1,5, Aug. 31 2014-Sept. 32014

[53] Shariati, N.; Rowe, W.S.T.; Ghorbani, K., "Highly sensitive rectifier for efficient RF energy harvesting," in Proc. European Microwave Conference (EuMC), 2014 44th, Hague, vol., no. pp.1190,1193, 6-9 Oct. 2014

[54] Parihar, P.D.; Kumar, P.; Jha, C.K.; Sharma, A., "Renewable battery charging method using CMOS RF energy harvesting circuit design," in Proc. Reliability, Infocom Technologies and Optimization (ICRITO) (Trends and Future Directions), 2014 3rd International Conference, Uttar Pradesh, India on, vol., no., pp.1,5, 8-10 Oct. 2014 